\title{
Professional educational training of French linguistics teachers in Kazakhstan and France
}

\author{
Elmira Aitenova - Galiya Abayeva - Farida Orazakynkyzy - Roza \\ Kassymova - Gulnar Mukhametkalieva
}

DOI: 10.18355/XL.2020.13.01.07

\begin{abstract}
Under the conditions of dynamic changes in Kazakhstan society and the modernization of the education system as a resource for these changes, i.e. the transition to a multi-level higher education, the problem of the quality of professional training of teachers is of particular importance. It defines the prospects for the development of education as an integral part of the culture of humanity and society as a whole. Successful professional activities of a modern teacher require a high level of competence, including in matters of professional behavior. From this point of view, the professional training of future teachers, which refers to the purposeful and controlled process of preparing the subject for the implementation of normative behavior in professional activities, becomes highly relevant. One of the urgent directions in studying foreign experience is the study of the theory and practice of teacher training in Western European countries, especially in France, and trying to apply some new effective ways in the Kazakhstan education system. The relevance of this problem is obvious because no matter what modernization takes place in the educational system, they all ultimately go to the teacher, whose level of professional training directly determines the state and prospects of the development of education in any country.The experience of teacher training in France, where reforming the system of pedagogical education is one of the priority areas of state policy, is entirely in tune with many contemporary problems of education. In the process of its development, the French system of teacher training has already solved the problems facing pedagogical education today: the development of state standards for teacher education, the search for effective ways to select applicants for pedagogical specialties, the modernization of the content of professional-pedagogical training, or the development and application of modern technologies in training. Hence the urgent need to analyze the current state of teacher education in France, to identify methods and forms of teacher training, as well as development prospects, provided, of course, their adequate and critical reflection is maintained.It is necessary to mention that this issue is being reviewed only from the side of vocational training but the comparative analysis between European and Kazakhstani systems has not been done in the aspect of its application to our system in the process of future specialist's competence formation. The purpose of this research is to explain and prove the necessity of education in the general system of education, and more specifically, in the area of professional education training of linguistic teachers. Since it concerns all teachers it does not matter which subject they teach and what language they are teaching, our topic pertains to the realm of general education (pedagogy). Furthermore, in teaching pedagogy to linguistic teachers we should pay attention to how to use the general methodology when applied in language teaching.
\end{abstract}

Key words: professional, training, French linguistics, teachers, Kazakhstan, France

\section{Introduction}

In the Republic of Kazakhstan, education is recognized as one of the long-term development priorities, the basis of the spiritual, social, economic, cultural progress of the state. The reform of the Kazakhstan education system is carried out on democratic principles, considering the achievements of world experience and national traditions. 
The main goal of the transformation is the implementation of a humanistic paradigm aimed at developing a student's personality with its inherent abilities, interests, individual characteristics, giving the educational process a definite positive personal sense. In the Republic of Kazakhstan, the educational policy of the state is implemented through the educational standard, which is focused on emphasizing the following as much as possible: bringing national education to the world level based on the principles of humanization, democratization, integration.

The key idea of the standard revolves around innovations. It is the introduction of a model of profile training for high school students, which allows to provide differentiation and individualization of education, development of readiness for choosing a future profession. The system of teacher education in France is represented by a network of interacting state higher education institutions of the Ministry of National Education, implementing a set of professional educational programs that ensure the formation of a professionally competent personality of the teacher based on the principles of democratization, continuity, openness, continuity. Based on the analysis of relevance and contradictions, the research problem is identified, which consists of identifying the pedagogical value of the French experience in training teachers for the development of teacher education in Kazakhstan.

The purpose of the study is to characterize the current state of the system of teacher education in France and Kazakhstan, to determine the features of the professional training of teachers in France, and to substantiate the pedagogical value of the French experience for the development of national pedagogical education.

Of great importance for the development of this problem were the works of French teachers on the problems of modernizing the content of pedagogical training and organizing the educational process in teacher training institutes: D. Ameline, D. Bansel, J. Berbom, M. Beaumard, P. Bouchard, M. Develey, A. Gyozeda, P. Gillet, J.-M. Leclerc, B. Meyer, F. Merier, G. Mialare, J.- L. Odyuk, B. Olivier, F. Perrenou, L. Tupin, J. Ussey, D Fernandez and others.

Teachers and psychologists have developed theoretical questions of training in pedagogical institutions of France in their studies: M. Berthelot, A. Vallon, R. Gal, J. Delay, E. Clapared, L. Cro, R. Cousine, J. Laf, F. Merrier, J. de Montmolen, B. Olivier, A. de Peretti, M. Postik, A. Prost.

Extensive material on the research topic is taken from pedagogical and socio-political periodicals: "Le Monde de l'éducation", "Cahiers pédagogiques "," Dossier Familial "," Le Délégué de l'Éducation Nationale "," Phosphore "," Le Nouvel Observateur "," L'Expansion "," Le Monde ".

An analytical review of the periodical pedagogical press in France allows us to conclude that teacher education has been and continues to be a priority in the development of the educational system in France, which determines the quality of professional training in all spheres of the functioning of society and ensures the training of a professionally competent personality of a teacher who is able to creatively approach solving professional problems and be responsible for the results of their teaching activities.

K. Allegre considered the practice of preparing first-year students to be inadmissible when a student admitted to the entrance examinations at the Pedagogical Institute had no idea of the future profession since he had never been to school. Therefore, proposals were introduced into the project to change the conditions for admission to the teacher training institute. When considering documents of candidates wishing to receive a pedagogical education, education providers were supposed to give preference to those who, in addition to being successful in studying at the university, gained some experience in professional activities in the field of education, for

XLinguae, Volume 13 Issue 1, January 2020, ISSN 1337-8384, eISSN 2453-711X 
example, worked as an assistant teacher, classroom supervisor, organizer of extracurricular activities, etc. (Cédelle L., 2000)

Two other essential innovations aimed at deepening the professionalization of future teachers of the mass school of France were provided for in the draft reform of teacher education. It was supposed to introduce passive practice and practice under the guidance of a mentor with a total duration of 3 to 4 weeks when studying in the first year of the institute. This practice was to become an obligatory element of preparation for all candidates who were admitted to competitive exams.

Another innovation was the introduction of a compulsory interview on a professional dossier as part of the second-semester training, the aim of which was to update the experience gained during passive practice.

The project noted that the leading share of practical training would be in the second year to give students the opportunity to apply the theoretical knowledge acquired in the process of preparation in practice. In the process of practical training, professionally important qualities are formed that are necessary for the implementation of the teaching profession. In addition, trainees acquire skills in transferring knowledge, leading a class, evaluating students' educational activities, their orientation, approaches to working with a heterogeneous class, raising morality and citizenship, and working with children with abnormalities in behavior, training for students living in problem neighborhoods, teamwork, etc.

The main task of a pedagogical university in modern conditions is the preparation of a teacher-researcher, highly professional, spiritually rich and moral person. A special place in this process is the updating of the content of education and training technologies. Without this, it is impossible to give the training of the future teacher a leading character.

The quality of the professional development of a teacher is largely determined by the nature of the content of instruction. The content of the training should cover a wide range of issues related to all areas and directions of pedagogical education. The teaching of any subject should be carried out in the context of the future profession of a student as a way of generalizing the knowledge, abilities, and skills acquired by him. The content of vocational teacher education has its specifics and differs significantly from vocational training in any other university. An analysis of the pedagogical literature suggests that the content of the training of future teachers at the French Pedagogical Institute is determined by the requirements of the current stage of development of society, the level of development of pedagogical science, and the characteristics of pedagogical activity.

Current trends in the development of society and the search for new effective forms and methods of teaching require the teacher to be able to reflectively think and master the content of developing pedagogy and methodology of activity. A modern teacher deals with a more complex student population than his predecessors. An increase in the number of students in a mass (public) school and an increase in the heterogeneity of the student body require considering the diversity of levels of preparation for school, abilities, interests, and psychological characteristics of students. Intellectualization and high dynamism of labor brought to the forefront the tasks of developing cognitive activity and creative forces of students, the formation of their skills of independent knowledge acquisition. (Wulfson B., 1996)

In the context of changing the priorities of educational tasks, the teacher must be highly educated and well-versed in his subject, as well as have effective psychological and pedagogical tools for stimulating and organizing children's activity. The tasks of quality training for future teachers require a harmonious combination of pedagogical, scientific, and professional knowledge and skills. With a further increase in the volume of knowledge, the selection of the content of teacher education is becoming especially relevant. 
In France, as well as throughout the world, over the past decades, attempts have been made to bring the content of professional teacher education of teachers in line with the development of the economy, technology, science, and society. (Lysova Ye., 1999) One of the modern trends in the development of the content of education is its standardization, which is caused by two circumstances: the need to create a unified pedagogical space in the country, as well as the task of integrating France into the European Union, which requires considering the development trends of the content of professional-pedagogical education in practice Western European countries.

An analysis of the periodical press of France shows that the K. Allegra project was aimed at deepening the professionalization of teacher training for public schools, an essential point of which was the organization of internships. Shortcomings in the organization of internships are manifested at the end of the practice. During an internship at school, students' communication with the institute is limited to one or two visits by tutors. These visits, on the one hand, are aimed at providing methodological assistance to the intern, and on the other hand, determine the evaluative attitude of the tutor to the work of the intern. In this regard, it was decided to create analytical groups for internships. The teacher of the institute should be able to lead such a group, able to analyze the causes of the problems that the trainee encountered during the internship and help the novice teacher with advice. (Baumard M., 2001)

Teacher education always focuses on current trends in the development of a multicultural educational space. The responsibilities of all universities were charged with providing third-year students with optional training modules, the aim of which would be to prepare diverse specialists. Candidates for possible participation in the CAPE competition (teacher of mother and elementary schools) could, along with studying at a university majoring discipline, study another one. For example, a student who is preparing to receive a license degree in mathematics will be able to receive philological training, and the future historian - study geography. In addition, students who decide to continue their studies at a pedagogical institute will have to undergo mandatory internships at schools. For future teachers of colleges and lyceums, passive practice at the school was foreseen before or during preparation for competitive tests so that they could join their future profession. All candidates, before appearing in front of the examination committee, should have gained some professional experience related to the school. At the same time, it was supposed to organize individualized and intensive preparation for oral exams. It was intended, first of all, for those who were admitted to competitive exams.

Globalization objectively dictates the need for unification of these systems, their alignment, coordination, but there is a line here that is simply dangerous to cross. Education should reproduce the core of national culture, the core of universal human culture, which includes the highest achievements of different cultures. In today's fastpaced world, teacher education, which is in the process of intensive transformation, is both an object and a subject of ongoing changes. The preservation, and, if possible, and the strengthening of the subjectivity of pedagogical education serves as the basic conceptual principle of not only reforms of national education systems, but also largescale integration processes unfolding in the European region.

Our study revealed that one of the directions of development of teacher education in France over the past decade was the modernization of the education content of future teachers, focused on the formation of qualities inherent in the personality of the future teacher, as well as on the practical training of students, provided both with organizational and pedagogical and scientific and methodological positions. The higher pedagogical school has moved away from the trend of traditional academism towards integration processes, the diversification of training courses, humanization, and the socialization of pedagogy and psychology courses.

XLinguae, Volume 13 Issue 1, January 2020, ISSN 1337-8384, eISSN 2453-711X 
Pedagogical education in France has always been considered the main element in the training of teachers to carry out their professional activities. Training in pedagogy is aimed at revealing the conditions and factors under which training and education achieve the greatest effect. On the one hand, students study the content and organization of pedagogical activity, and on the other, the activity of students. Questions of the theory are associated with the educational work in the classroom, with the methodology of extracurricular work, etc. At present, with all the global problems facing educational systems, this area of training is given decisive importance. Particular attention in the preparation of teachers for the mass school is drawn to the issues of adaptation to school life and the education of immigrant children, and assistance to children with learning difficulties. The relevant sections are included in pedagogy courses on the recommendation of the European Council for Education, whose task is to develop cooperation between European countries in order to harmonize education systems.

Disciplines of the pedagogical cycle are the most important sources from which the student draws knowledge and love for the profession of teacher-educator. Pedagogical training is not limited to simply acquaintance with the reception of work or the practice of simple professional acts to combine action and thought, theory and practice. Pedagogical training is nevertheless chronologically secondary to academic training, in the sense that it is started after the end of the first cycle of study at the university. The main content of professional training preceding the choice of a specialty is comprehensive humanitarian knowledge, which serves as the basis for special training. Teacher training is based on thinking skills, working methods, acquired concepts and knowledge, which are the result of past and present academic training.

In France, a lot of work is being done to modernize the content of education. New realities in the development of education brought to life the regionalization of education, which was manifested in the requirement to consider a number of regional features in the training of teachers in a pedagogical university. Along with the uniform training for all students in basic courses, in accordance with regulatory documents, differentiation of the content of education is also carried out considering the specifics of the region. Among the list of optional courses at French pedagogical institutes are contemporary foreign languages and culture, regional languages and culture (for example, the Pedagogical Institute in Rennes offers a Breton language course and a special competition for students wishing to study in Breton, Marseille the institute offers the study of the Languedoc language, etc.). (Reboul O.,1999)

Such locality of teacher training, in our opinion, leads to a decrease in the level of professional teacher education.

During the oral professional exam for admission to the competitive entrance examinations to the institute, evaluated are not only the expressive and communicative abilities of the candidate but also knowledge of the educational system. For this purpose, freshmen are offered a special module "Education System". This preparation, which all students enroll in, regardless of their future specialty, is carried out in the educational institution with the participation of the teacher of the pedagogical institute and the director of the school. Its purpose is to familiarize students with the principles of the functioning of the education system, with the training cycles, with the variety of general educational institutions, with the activities of the administration and the teaching staff, documentation, etc. Students are also introduced to the documentation and information centers of colleges and lyceums, and the opportunities that documentary schools provide for teachers of various disciplines. In addition, within the framework of this module, an introductory practice (stage filé) is provided (4-6 days, 3 hours each), during which students go to different classes in 
various types of educational institutions. First-year education includes the passage of passive practice (stage bloqué) (twice in 2 weeks), which takes place in the same class and is aimed at familiarizing yourself with the content and training programs of the discipline that the student is going to teach in school. During passive practice, the trainee attends classes at the teacher's school, to which he is attached for the period of the internship, for a specific purpose, to trace either the use of teaching methods or the organization of group work, etc., he learns to plan a lesson, independently carries out some types of work in the classroom, for example, checks homework, helps students who have difficulty learning, etc.

When studying in the second year, which bears the whole burden of responsibility for vocational training, the study of various aspects of the teaching profession is based primarily on the analysis of teaching practice and the experience of interns.

In addition, the obligatory module "Maternal School" was introduced for trainees future teachers of elementary schools, designed for 24 hours of preparation. The entire training course for this module provides for 8 three-hour workshops, which are distributed throughout the year. These seminars deal with various issues of the theory and practice of teaching and educating preschoolers. The content of this module primarily covers aspects such as child development (emotional, cognitive, physical and psychological); acquaintance with the history, functioning, organization, education of children in the mother's school; study of government laws and regulations on maternal schools; familiarity with the specifics of work in this educational institution. In these classes, devoted primarily to working with children of the younger group of the mother school, the trainees learn to develop work plans, draw up work schedules, pay attention to the activities of babies throughout the day, etc. Trainees are given the opportunity to supplement their knowledge of the specifics of work in the mother's school during class in the vocational training group while undergoing teaching practice, and in studying disciplines. (Coutty M., 2002)

The education system throughout the world is experiencing an unprecedented period of change in its desire to keep up with the information society. Since teachers act as catalysts for the successful development of an information society, they should be characterized by such qualities as the desire to continuously increase the level of their knowledge, professional creativity, reflective skills, technological mobility, the ability to perceive experience and readiness to innovation, etc. A new level of their professional activity presupposes the presence of social and emotional, as well as technical and intellectual components that allow you to establish emotional connections, both with children and between them, to lay the foundations of such character qualities as: empathy, tolerance, etc. (Hargreaves E., 2001)

Fundamentally new tasks facing the school cannot be solved with the help of traditional didactic means. The aim of modern pedagogical education is to prepare the graduate not so much for the translation of knowledge as for the ability to ensure their assimilation. (Barthelemy D., 2000)

To organize the pedagogical process that meets the listed tasks and requirements, it is necessary to provide for the appropriate methods and forms of organization of the educational process, to introduce innovative pedagogical technologies. An analysis of the pedagogical literature on the problem under study showed that the 20th century was marked by intensive experimentation aimed at finding new ways of training specialists. The introduction of training technologies, which began in the second half of the 20th century, remains an important source of progress in training specialists. Without abandoning the application of traditional methods of upbringing, teachers sought to "technologicalize" the learning process, to make it more effective by using the latest achievements in psychology, sociology, psychotherapy, cybernetics and other branches of modern scientific knowledge. (Pilipovsky V., 1994)

XLinguae, Volume 13 Issue 1, January 2020, ISSN 1337-8384, eISSN 2453-711X 
The technological construction of training affected such basic components of the teaching method as the goal of the teacher and students, their means, the mechanism for promoting students to the goal and the achieved result. However, in general, the "technological" approach to methods, in our opinion, was subordinated to the task of increasing the effectiveness of reproductive education.

The scientific and technological revolution pushed for the development of the idea of programming educational activities, involving in the organization of the learning process the techniques developed in the "personality-oriented" psychology. The emphasis on the personal importance of teaching meant subordinating the entire content of the educational activity to the task of preserving and developing the unique individuality of each student, with which the activities of the teacher correlate as with the ultimate goal. (Klarin M., 1984)

The experimental work was carried out in four stages - ascertaining, formative, generalizing, implementation. The results of the ascertaining stage of the experimental work showed a low level of professional and pedagogical competence of future teachers, which is largely due to the inefficiency of the traditional approach to their professional training in the process of teaching practice. It was found that about $68 \%$ of students have an average level of professional and pedagogical competence; about $32 \%$ is low; students with a high level were not identified.

In the process of the forming stage of the experimental work, the effectiveness of the model of professional training of future teachers in the conditions of the integration of education in the university complex and monitoring of its effective functioning was checked. In accordance with the proposed model, the main areas of work for the training of future teachers in the integration of education in the university complex were identified, providing for organizational, educational, teaching and research units. In accordance with the logic of constructing a structural-functional model as a result of monitoring the effective functioning of the developed model, an effective combination of forms, methods and means of organizing the pedagogical process is determined.

In order to confirm the hypothesis of the research during the formative phase of the experimental work, an intermediate section was conducted to identify the dynamics of the level of professional and pedagogical competence of future teachers and determine the effectiveness of the implementation of the model of professional training of future teachers in the context of the integration of education in the university complex and a control section to establish the level professional and pedagogical competence of future teachers at the end of the experiment work.

\section{Conclusion}

The theoretical significance of the study lies in the fact that it defines the content of the concept of "teacher education system in France". The theoretical significance of this work is also ensured by the fact that the system of professional-pedagogical training of teachers for the French mass school, which has undergone dramatic changes in the last quarter of the 20th century and is currently undergoing reform, has become the subject of special research in $\mathrm{n}$ comparative pedagogy. The conclusions contained in the study can be considered in the theoretical substantiation of the content of teacher education.

The practical significance of the study lies in the possibility of using its results in the training of teachers of the national comprehensive school, in developing specific recommendations on the use of foreign experience in the system of teacher education in . The research materials can be used when giving lectures on the history of pedagogy and education, regional studies, special courses on foreign and comparative pedagogy in the universities of our country, when writing student coursework and diploma works on the problem of teacher education in France. Equally important in scientific research is the differentiated isolation of the positive aspects in the practice 
of teaching at the French higher pedagogical school and the design on this basis of the process of improving the training of $n$ teachers.

\section{Bibliographic references}

BARTHELEMY, D. - RIBA, R. - BIRZEA, C. - LECLERC, J.M. The European Dimension in Secondary Education, Standards and Monitoring in Education, n. 6, p.26-43.

AUDUC, J. - LES L.1998. institutions scolaires et universitaires, Paris, 128 p.

BAIETTO, M.C. - GADEAU L. 1995. Clinique et analyse des pratiques, Cahiers pédagogiques, n. 338, pp. 20-22.

BANSSE, D. 1996. Pour votre documentation. A travers le B.O.//Le Délégué de l'Education Nationale, n.167, pp. 24-27.

BAUMARD, M. 1999. Le concours d'abord, le métier ensuite//Le Monde de l'éducation, n. 275, pp. 26-27.

CEDELLE, L. 2000. La reforme des IUFM : des stages et des tuteurs//Le Monde de l'éducation, n. 279, pp. 56-57.

CORNU, L. - VERMEREN P. 2000. La formation des professeurs à «l'impossible métier » In: Le Monde de l'éducation, n. 283, p.55-56.

COUTTY, M. 1998.De la vocation à la profession, Le Monde de l'éducation, n. 262, pp. 40-41.

COUTTY, M. IUFM, 1999. un bilan mitigé après dix ans d'existence, Le Monde de l'éducation, n. 275, pp. 22-24.

DELAIRE, G. 1997. La vie scolaire. Principes et pratiques, Nathan, Paris, 174 p.

DEVELAY, M. 1991. Les champs disciplinaires. L'enseignement des matières, Cahiers Pédagogiques, n 298, pp. 12-15.

LE GUIDE DU PROFESSEUR. 1989, Recueil de textes officiels et commentaires, CRDP de Paris, 180 p. Le Guide de vos études supérieures, Phosphore, n. 32, 106 p.

HUBA, J. - LECLERCQ, J.-M. 1984. Les enseignants dans les sociétés modernes//Notes et études documentaires, n. 4775, Paris, 150 p.

INSTITUT NATIONAL D'ETUDE DU TRAVAIL ET D'ORIENTATION PROFESSIONNELLE 1993, Paris, 28 p.

Les IUFM, 1999. sont-ils archaïques? In: Le Monde de l'éducation, n. 275, p. 8.

LARONCHE, M. M. 2003. Ferry veut réformer les IUFM en renforçant le rôle des universités dans la formation des enseignants In:Le Monde, p. 5.

LECLERCQ, J. - RAULT, CH. 1990. Les systèmes éducatifs en Europe. Vers un espace communautaire? Notes et études documentaires, Nancy, Bialec, 152 p.

LEGRAS, J.M. 1995. Des IUFM ... pour l'unification de la formation des maîtres, Cahiers pédagogiques, n. 335, pp. 37-38.

PROST A. 1960: enfin une administration pour la réforme, Le Monde de l'éducation, n. 310, pp. 68-69.

REBOUL, O. 1992. La philosophie de l'éducation, Presses Universitaires de France, Paris, $128 \mathrm{p}$.

ROSAVALLON, P. 2001. A-t-il converti la gauche au capitalisme?, In: L'Histoire, n. 253, $64 \mathrm{p}$.

SERY, M. 2002. Dans l'éducation, le défi est de taille, Le Monde de l'éducation, n. 299, pp. 42-44.

WULFSON, B. L. - MALKOVA 3. A. 1996. Comparative pedagogy, In: Institute of Practical Psychology, Voronezh, NPO MODEK, 256 p.

XLinguae, Volume 13 Issue 1, January 2020, ISSN 1337-8384, eISSN 2453-711X 
LYSOVA ,YE. B. 1999. Problems of the content of education in French pedagogy, Pedagogy, n. 3, pp. 101-108.

HARGREAVES, E. - LUO L. 2001. The profession of a teacher at the turn of the century: existing paradoxes, Prospects: Comparative studies in the field of education, vol. XXX, n. 1, pp. 103-122.

PILIPOVSKY, V. YA. 1984. Basic worldview orientations of bourgeois concepts of education, "Bourgeois pedagogy at the present stage: a critical analysis" , Ed. Malkova 3.A., Wulfson B.L. In: Pedagogy, 256 p.

KLARIN, M.V. 1984. Searches for new teaching methods, "Bourgeois pedagogy at the present stage: a critical analysis" Ed. Malkova 3.A., Wulfson B.L. In: Pedagogy, $256 \mathrm{p}$.

Words: 4876

Characters: 32385 (17,99 standard pages)

Elmira Aitenova

Abay KAZNPU

Almaty

Kazakhstan

Abayeva Galiya

Kazakh State Women's Pedagogical University

Kazakhstan

Farida Orazakynkyzy

Roza Kassymova

Gulnar Mukhametkalieva

al-Farabi Kazakh National University

Al-farabi avenue 71

Almaty

Kazakhstan 